\title{
A Survey on Enhanced Smart Micro-Grid Management System with Modern Wireless Technology Contribution
}

\author{
Lilia Tightiz $(\mathbb{D}$, Hyosik Yang *(1) and Mohammad Jalil Piran \\ Department of Computer Engineering, Sejong University, 209, Neungdong-ro, Gwangjin-gu, Seoul 05006, Korea; \\ liliatightiz@sju.ac.kr (L.T.); piran@sejong.ac.kr (M.J.P.) \\ * Correspondence: hsyang@sejong.edu; Tel.: +82-02-3408-3840
}

Received: 12 March 2020; Accepted: 23 April 2020; Published: 4 May 2020

check for updates

\begin{abstract}
Micro-grid (MG) deployment has dramatically become more popular with the high penetration of renewable energy resources (RER). This trend brings with it the merits of independent power grid clean energy resource-based systems, and simultaneously the demerits of an unstable grid due to the intermittent nature of RER. Control and monitoring of MG through robust and ubiquitous communication system infrastructure is the solution to overcoming this intermittency. There has been an increasing focus in recent years on using wireless communication technologies as a prominent candidate in holistic proposal for the micro-grid management system (MGMS). The MGMS has been developed using the multi-agent system (MAS), multi-micro-grid (multi-MG), Internet of things (IoT) integration, and cloud concepts requiring new communication specifications, which can be satisfied by next-generation wireless technologies. There is, however, a lack of comprehensive corresponding investigation into management levels of MG interaction requirements and applied communication technologies, as well as a roadmap for wireless communication deployment, especially for the next generation. In this paper, we investigate communication technology applications in the MG and focus on their classification in a way that determines standard gaps when applying wireless for MG control levels. We also explore and categorize the literature that has applied wireless technologies to MG. Moreover, since MGMS has been revolutionized by attaching new technologies and applications to make it an active element of the power system, we address future trends for MGMS and offer a roadmap for applying new enhancements in wireless technologies, especially the fifth generation (5G) of wireless networks with its exclusive characteristics, to implement this novel approach.
\end{abstract}

Keywords: micro-grid; energy management system; IEC 61850; 5G; LoRa; multi-agent system

\section{Introduction}

Due to problematic issues with fossil fuels such as the limited resources, increasing greenhouse gases, and air pollution, new resources of energy, including solar, wind, tidal, etc. have been introduced, known as renewable energy resources (RER), and have overcome environmental issues with fossil fuels [1]. One of the most prominent advantages of RER is the end of dependency on conventional power plants and a centralized electricity network, which makes them sustainable candidates for distributed electricity generation, particularly in remote places. This specification, along with the development of communication technologies that facilitate information exchange in remote places to cover control, protection, and administration requirements of this distributed grid, have led to increasing RER use in the electricity grid, especially in the form of micro grids (MG) [2]. Based on the Institute of Electrical and Electronics Engineers (IEEE) standard 2030.7-2017 [3], MG is defined as a "group of interconnected loads and distributed energy resources with clearly defined electrical 
boundaries that act as a single controllable entity concerning the grid and can connect and disconnect from the grid to enable it to operate in both grid-connected or island modes". MG penetration is increasing, as it will decrease the cost of electricity transmission infrastructure by using RER. Corresponding to the definition of MG, there are two performance modes: islanded mode, and grid-connected mode. In islanded mode, MG should be able to work as an independent grid and supply consumers alone. On the other hand, in grid-connected mode, the connection of MG to a utility grid defeats the risk of unavailability owing to natural resource features, and offers other benefits related to participation in the electricity market as a prosumer, specifically selling over-produced electricity or buying it in the case of resource unavailability or system failure. All these advantages would not be viable without a robust communication system.

There has been a plethora of research about the optimal control, protection and management of MG [4-7], which have revealed the role of automation and smartization to achieve above-mentioned MG profit to be undeniable; however, communication structure and specification of the system are the key factors of all these scenarios [8-10]. A large number of possible communication protocols and configurations have been applied in MGMS depending on the control and protection scenarios of the system, geographical location of MG, initial investment and maintenance budget, the importance of loads, number of distributed energy resources (DER), traffic rates of the communication system, and so on. Many authors have attempted to find the best communication structure for international standards, such as the International Electrotechnical Commission (IEC) 61850, IEEE 1547, and IEC 61400-25 [11-14]. IEC 61850 is a standard of the communication protocol of automation in the power industry. This standard considers communication within power system substations and uses an open system interaction (OSI) model as a communication stack for data exchange in the local area network (LAN) in its first version. It has been developed for the intelligence of the entire breadth of the power system and interacts with MG by adding IEC 61850-7-420, IEC 61850-90-7, IEC 61850-8-2, and IEC 61850-9-12. These new parts specify information models for exchange information with DER along with the definition of communication stacks for wide-area network (WANs). IEC 1547, which is a standard of interconnection between DER and electric power systems, deals with safety, protection, power quality, and information exchange requirements of DER, as well as alternative configurations for MGMS. IEC 61400-25, which is a standard of communications for the monitoring and control of wind power plants, provides uniform model information for exchanging data. These standards facilitate control, protection, and management modeling of MG. In the case of communication technology deployment, studies have categorized MG interactions into two groups: wired and wireless. While RS-232, RS-485, Power Line Carrier (PLC), optical fiber, and ethernet are commonly used wired technologies in MG communications, ZigBee, Bluetooth, Wi-Fi, WiMAX, Global System for Mobile (GSM), 5G/4G/3G/HSPA, LoRa, and satellite communication are wireless ones [15-20]. Due to wireless technology advantages in comparison with wired technology, such as cost effectiveness, convenient installation, portability, low risk of ground potential issues, and scalability, an investigation into employing this technology in MGMS should be undertaken.

\subsection{Related Works}

Protection, control, management, and communication requirements, as well as the intermittent characteristic of RER as the main element of MG, has made this research area a trend in the power industry. This trend is divided into two different domains: electrical and communication. The performance of the predecessor is dependent on the successor. As shown in Table 1, several researchers have attempted to recognize communication architecture and technologies adapted to MG requirements as an interactive smart element of the public electricity grid. Safdar et al. [21] divided communication in MG into three levels: home area network (HAN), field area network (FAN), and WAN. The authors proposed appropriate communication technologies for each level. Based on the requirements of physical connections, they made wireless technology attractive for communication in MG. The authors in this paper mentioned reliability, quality of service (QoS), security, complexity, 
standardization, and efficiency as challenges in the communication infrastructure of MG while disregarding enough intention to standard protocols, and their relevant constraints, which have had a significant effect in communication technology employment. MG testbed structures and applied communication technologies were reviewed comprehensively in [22]; however, this review focused on characteristics of implemented structure communication technologies, and future trend guidelines were missing. Bani-Ahmad [23] then clarified the data flow and communication protocols and standards of MG, such as the Internet Protocols Suite, Modbus, DNP3, and IEC 61850, and focused on MG physical communication links in two parts: wired physical links and wireless physical links. Although this survey satisfied the protocol critical characteristics of communication in MG in comparison with typical IT systems, there was no classification of the application of highlighted technologies in MG communication structure. The role of communication in MG, wired and wireless technologies, and their limitation in MG applications were analyzed in [16]. Mavrokefalidis et al. [24] provided a brief overview of the communication infrastructure and challenges of applying wireless communication in MG. Marzal et al. [20] investigated the feasible network topology for smart MG along with MG evolution. The authors then noted smart MG issues, including bandwidth, latency, reliability, and cybersecurity, and studied communication protocols and technologies through the literature. The categorized communication technologies based on application and reviewed their characteristics and issues, as discussed in [25] and studied in [26] after the comparison of specifications of wired and wireless communications, which concentrated on satisfying communication requirements and the architecture of smart inverters in MG.

Table 1. Present and related works-a comparison.

\begin{tabular}{|c|c|c|c|c|c|c|c|c|}
\hline \multirow{3}{*}{ Reference } & \multirow{3}{*}{ Year } & \multicolumn{7}{|c|}{ Contribution } \\
\hline & & \multicolumn{3}{|c|}{$\begin{array}{c}\text { MG Communication } \\
\text { Specification Requirements }\end{array}$} & \multicolumn{2}{|c|}{$\begin{array}{l}\text { MG Communication } \\
\text { Technologies }\end{array}$} & \multirow{2}{*}{ Future Trends } & \multirow{2}{*}{ Roadmap } \\
\hline & & Standard & Control & Application & Wired & Wireless & & \\
\hline S.Safdar et al. [21] & 2013 & $x$ & $x$ & $\checkmark$ & $x$ & $\checkmark$ & $x$ & $x$ \\
\hline L.Mariam et al. [22] & 2013 & $\checkmark$ & $x$ & $x$ & $\checkmark$ & $\checkmark$ & $s$ & $x$ \\
\hline Bani-Ahmed et al. [23] & 2014 & $s$ & $x$ & $x$ & $\checkmark$ & 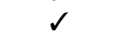 & 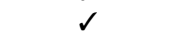 & $x$ \\
\hline P.D.Chavan et al. [16] & 2016 & $\checkmark$ & $\checkmark$ & $\checkmark$ & $\checkmark$ & $\checkmark$ & $x$ & $x$ \\
\hline C.Mavrokefalidis et al. [24] & 2017 & $x$ & $x$ & $x$ & $\checkmark$ & $\checkmark$ & $\checkmark$ & $x$ \\
\hline S.Marzal et al. [20] & 2018 & 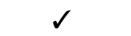 & $\checkmark$ & $\checkmark$ & $\checkmark$ & $\checkmark$ & $\checkmark$ & $x$ \\
\hline T.T.Mai et al. [25] & 2018 & $\checkmark$ & $\checkmark$ & $\checkmark$ & $\checkmark$ & $\checkmark$ & $x$ & $x$ \\
\hline B.Arbab-Zavar et al. [26] & 2019 & $x$ & $x$ & $\checkmark$ & $\checkmark$ & $\checkmark$ & 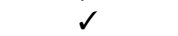 & $x$ \\
\hline Present Paper & 2020 & $\checkmark$ & $\checkmark$ & $\checkmark$ & $\checkmark$ & $\checkmark$ & $\checkmark$ & $\checkmark$ \\
\hline
\end{tabular}

All these attempts investigated communications requisite for and technologies applied in MG and their specifications and applications, although some of the following aspects, which affect communication requirements in MG, have been neglected. Applying energy storage systems (ESS), RER, and responsive loads (RL) along with the introduction of new concepts in a smart grid (SG) and MGMS architecture such as MAS, multi-MG, and IoT integration, make MG an integrated part of the main grid. In this scenario, MG cooperates in the electricity market as a prosumer and supports the main grid by providing ancillary services (AS) such as demand response (DR), power system frequency, and voltage stability, as well as black-start aid and electricity market contribution by using technologies such as vehicle-to-grid (V2G), smart inverters, and so on. Moreover, communication protocol standards, which are applied in MG communication, need revising to attain appropriate a communication infrastructure for these new technologies. To produce these aspects, we focus on MG as SG tiles, and cut short the path to the development of SG penetration [27]. We will provide a supervisory hierarchical structure for MG corresponding to the SG conceptual model, as well as clarifying the situation of this structure in the distribution management system (DMS). Another idea behind this hypothesis is using MG to help power system stability by splitting the power grid into islands [28]. Table 1 shows how this paper, in comparison with related works, involves all examined MG control structures and wireless technology applications, in order to detect a roadmap for exploiting these technologies. 


\subsection{Contribution}

To address the above-mentioned issues, the main contributions of this paper are summarized as follows:

- Investigation of MG communication requirements based on MGMS and DMS requirements.

- Study of relevant communication standards from the perspective of smart MG and standard revision requirements in a way facilitating wireless deployment in MG communication.

- Study of the deployment of wireless communication applications in MG through the classification of literature based on applications and methods.

- Determination of wireless technology applications in MG concerning communication requirements and standards of each application.

- Investigation using new wireless technologies such as 5G to attain a roadmap for wireless application in new MGMS trends such as MAS and multi-MG.

The remainder of this paper is organized as follows. Section 2 is about the concept of MG focusing on electrical and communication structures and specifications. Section 3 introduces communication standard protocols and their revision requirements to facilitate wireless deployment in MGMS. Communication technologies and their applications in each supervisory level of the MGMS are discussed in Section 4. To provide a roadmap for using new technologies in MG focusing on wireless technology and more specified enhanced ones such as $5 \mathrm{G}$ in Section 5, we classified the literature based on its objectives, MG application, and method qualification when using wireless technologies in MG environments. After opening new horizons for our paper research area in Section 6, our attempt is finalized in Section 7.

\section{MG Concept and Requirements}

\section{1. $M G$ Structure}

MG, according to the definition proposed in the introduction to the paper, includes DER, which can be RER as conventional resources, ESS as an infrastructure of energy market contribution, or AS in the absence of DER, loads, and finally a breaker at the point where MG connects to the main grid. This collection of elements has two modes of operation, specifically, grid-connected and islanded mode. In grid-connected mode, they receive services or provide services for the main grid, whereas in islanded mode, they should be able to manage all control, stability, and protection requirements. Achieving these characteristics requires a smart structure for MG, and its elements should be developed with these requirements in mind. It is noted that the penetration and integration of smart MGs should be in the form of tiles facilitating the implementation of SG. Figure 1 is a visualization of this idea, where MG structure meets the conceptual model of SG. SG has seven sectors [28]: Customer, Service Provider, Transmission, Distribution, Bulk Generation, and Market. Adapting the MG structure to SG structure, while the role of generation, transmission, distribution, operator, and consumer is clear, as can be seen in Figure 1, the maintainer acts as a service provider and the aggregator is in the market domain. The performance of each entity is clarified here.

- MG Aggregator: This participant is in charge of gathering information about energy marketing participants for MG.

- MG Operator: This party monitors MG and controls its performance through local and remote services.

- MG Maintainer: This agent is responsible for the accurate performance of MG by providing maintenance services in case of failure according to the received reports.

- MG Controller: Aggregator, Maintainer, and operator interact through this part with each other and DER, facilitating the Energy Management System (EMS) control level. 
- Local Utility: Local utility is the MG utility neighbor who connects to MG through the Point of Common Coupling (PCC) and interacts with MG to coordinate the provision of AS in grid-connected mode.

As well as embedding MG in SG domain, Figure 1 conveys a hierarchical control strategy of smart MG by introducing three supervisory levels, namely advanced metering interface (AMI), EMS, and DMS.

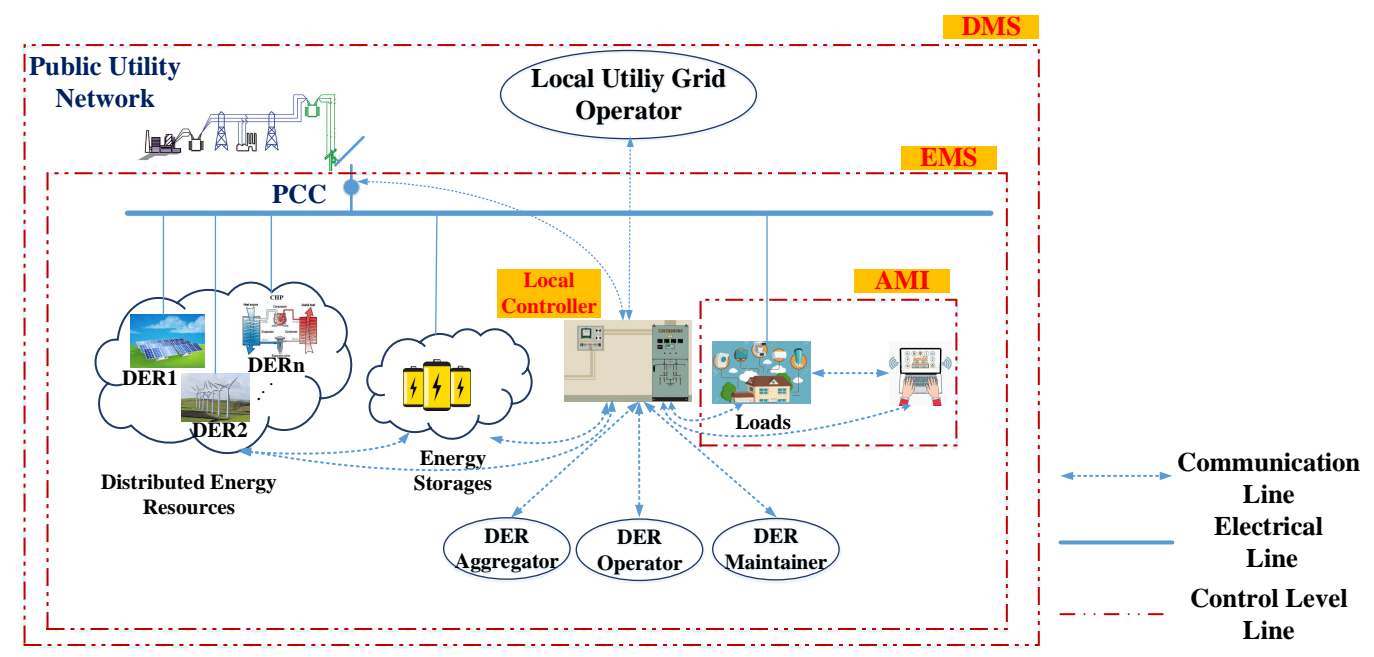

Figure 1. MG architecture.

- $\quad$ AMI: The first control level is related to load control. In this paper, this control level is considered in the scope of MG. Energy consumption of smart appliances is monitored through smart meters and the AMI control level is responsible for sending this information to the higher level, which is EMS. AMI makes it possible to cooperate with RL in load shedding, peak shaving, and other services.

- EMS: The second control level of MG is EMS, which is responsible for control demand and supply in MG based on information receives from DER, ESS, and loads. EMS has a key role in MGMS and provides a schedule for each MG element operation through the optimization algorithm in both grid-connected and islanded modes of MG. EMS decides MG contribution in AS provision for the utility grid in a way that determines the contribution portion of each source.

- DMS: The third control level is responsible for the control, monitoring, and reliability of the distribution network. This supervisory control level reveals when MG will be able to work in grid-connected and supply loads from the main grid or provide AS for utility and, in case of any failure in MG, it will disconnect from the main grid. There could be several MGs in DMS territory as shown in Figure 2.

The hierarchical control level of MG can be implemented through a centralized or decentralized approach. In the centralized approach, each element receives setpoints from a central controller and follows a global objective, while in decentralized approach decision making in each level control is distributed. In distributed fashion, each element has been considered to be an agent which independently decides to participate in SG or MGMS. This offers advantages such as plug-and-play patterns, no need for a dedicated communication infrastructure, fast response to system failure, and power grid consisting of independent entities [29,30]. Moreover, due to the significant advantages of MGMS characteristics when deploying MAS, trends toward the implementation of SG in the form of multi-MG have been augmented recently. It is estimated that future SG would be multi-MG that works in the MAS environment [31,32]. Figure 1 proposes the control level of individual MG without centralized and decentralized approach. The local controller in this figure can be considered to be located in EMS, or distributed in each element. 


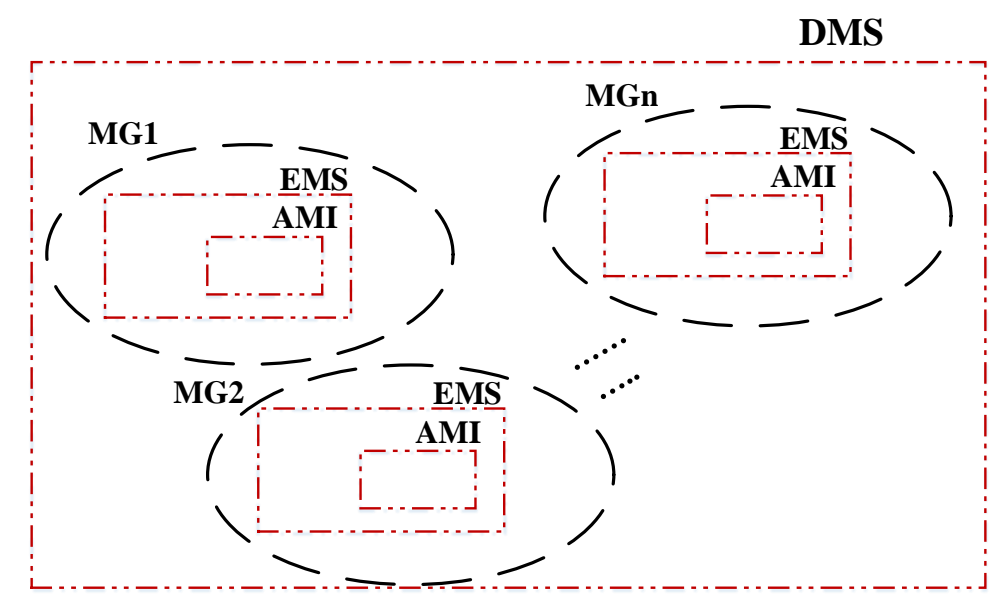

Figure 2. DMS supervisory level domain.

\subsection{MG Communication Requirements}

To detect efficient and appropriate communication technology for MG, we need to ascertain the specifications and constraints of information exchange in each supervisory level. Figure 3 shows a comparison of AMI, EMS, and DMS characteristics based on data rates, reliability, coverage, delay, complexity, security, and benefits per cost. This figure ensures each control level of MG has its communication requirements. While all control levels require a highly reliable and secure communication, their data rates and delay characteristics increase according to their coverage characteristic. The other important specification for communication infrastructure is backup power, which ensures the performance of communication during any outage and is proportional to the critical mission of each level control from zero for AMI, as interacting with meters increases to one hour for EMS, and 72 hours for DMS. In the SG environment, there is a hierarchical communication level including HAN, FAN, and WAN. This classification can be followed by MG. While HAN contains loads such as smart appliances and electric vehicles (EV), which can be automated and programmable through home energy management systems (HEMS) to provide AS for utility grid such as DR, FAN coordinates among DER, ESS, operators, and energy marketing entities, hence needing higher bandwidth than HAN. At the highest level, WAN embraces information exchange between EMS and DMS when MG works in grid-connected mode. Communication specifications of applications in MG are summarized in Table 2 [33].

Table 2. Communication specification application in MG.

\begin{tabular}{|c|c|c|c|}
\hline Communication Level & Application & Bandwidth & Latency \\
\hline \multirow{3}{*}{ HAN } & HEMS & $9.6-56 \mathrm{kbps}$ & $200 \mathrm{~ms}-2 \mathrm{~s}$ \\
\hline & EV Charging & 9.6-56 kbps & $2 \mathrm{~s}-5 \mathrm{~min}$ \\
\hline & V2G & $9.6-56 \mathrm{kbps}$ & $2 \mathrm{~s}-5 \mathrm{~min}$ \\
\hline \multirow{2}{*}{ FAN } & AMI & node:10-100 kbps backhaul: 500 kbps & $2-15 s$ \\
\hline & DER and ESS & $9.6-56 \mathrm{kbps}$ & $20 \mathrm{~ms}-15 \mathrm{~s}$ \\
\hline \multirow{2}{*}{ WAN } & DR & $14-100 \mathrm{kbps}$ & $500 \mathrm{~ms}-$ several min \\
\hline & DMS & 9.6-100 kbps & $100 \mathrm{~ms}-2 \mathrm{~s}$ \\
\hline
\end{tabular}




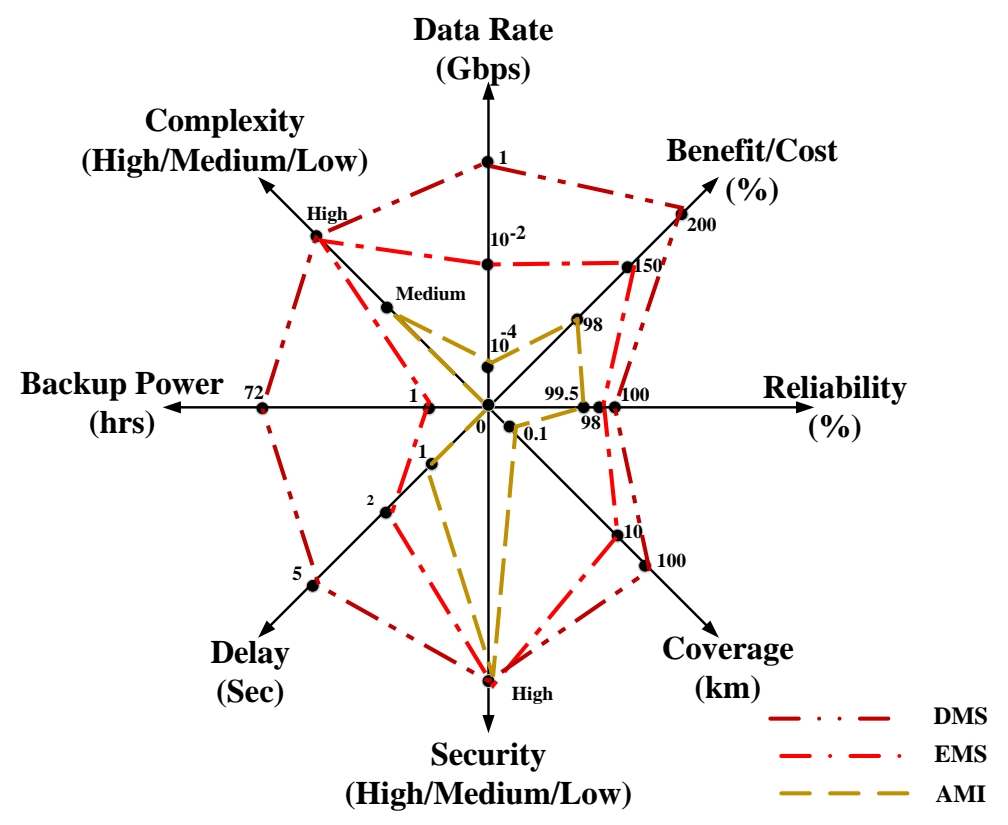

Figure 3. Comparison of MG control levels characteristics.

\section{MG Communication Protocols and Standards}

There is a plethora of standards that embody all aspects of MG electrical and communication requirements. Table 3 depicts all communication-relevant standards of MG, which have been clarified in the following.

Table 3. MG management- and communication-relevant standards.

\begin{tabular}{|c|c|c|c|}
\hline & Standard Title & Reference & Title \\
\hline \multirow{5}{*}{ IEC } & $61850-7-420$ & [34] & $\begin{array}{l}\text { Basic communication structure-Distributed } \\
\text { energy resources logical nodes }\end{array}$ \\
\hline & $61850-8-2$ & [35] & $\begin{array}{l}\text { Specific Communication Service Mapping } \\
\text { (SCSM)-Mapping to eXtensible Messaging } \\
\text { Presence Protocol (XMPP) }\end{array}$ \\
\hline & $61850-90-7$ & [36] & $\begin{array}{l}\text { Object models for power converters in } \\
\text { distributed energy resources (DER) systems }\end{array}$ \\
\hline & $61850-90-12$ & [37] & Wide-area network engineering guidelines \\
\hline & $61400-25-2$ & [38] & $\begin{array}{l}\text { Communications for monitoring and control of } \\
\text { wind power plants-Information models }\end{array}$ \\
\hline \multirow[t]{2}{*}{ IEEE } & 1547 & [39] & $\begin{array}{l}\text { IEEE Standard for Interconnection and } \\
\text { Interoperability of Distributed Energy Resources } \\
\text { with Associated Electric Power Systems } \\
\text { Interfaces }\end{array}$ \\
\hline & 2030 & [40] & $\begin{array}{l}\text { Smart Grid Interoperability of Energy } \\
\text { Technology and Information Technology } \\
\text { Operation with the Electric Power System (EPS), } \\
\text { End-Use Applications, and Loads }\end{array}$ \\
\hline
\end{tabular}

\subsection{IEC Standards}

\subsubsection{IEC 61850}

IEC 61850 is an international standard of communication networks and systems for power utility automation. This standard in the 2003 edition focused on the automation of power system substations 
and was divided into three levels: Process, Bay, and Station. In the process level, measurement equipment such as current transformers (CT), potential transformers (PT), or phasor measurement units (PMU) are located and send measurement data to the bay level, which is the place of intelligent electronic devices (IED) issuing control and protection commands based on the received information. The process level communicates with one or more bays, and even the whole substation, as well as exchanging information with the engineering workplace for remote control commands. All of this information exchange in a form of three types of the message, including manufacturing message specification (MMS) for non-critical information and in the format of request-response, generic object-oriented substation event (GOOSE) for critical information with high priorities such as trip command and sampled value (SV) for measurement units with high priority. GOOSE and SV are of multicast format. Each of these messages has its time limitation and is mapped according to the communication stack proposed in part 8-1 of the standard, which uses an open system interconnection (OSI) model and Ethernet as a physical layer in the LAN environment. In MG, an IED is located in each DER for the control and protection of objects. The nature of MG is that it is positioned in remote places desiring interconnection with the main grid through WAN. An extension of IEC 61850 in successive editions by information model supporting MG in part 7-420, 90-7, and providing a communication stack for interconnection in WAN based on applying eXtensible Messaging and Presence Protocol (XMPP) for mapping information in part 8-2 makes this standard appropriate for use in the MG communication environment. However, it is noted that other IoT protocols are suggested in other literature, and laboratory experiences perform better than XMPP in comparison with QoS, implementation infrastructure requirements, and future development specifications [41,42].

\subsubsection{IEC $61400-25-2$}

This standard presents a uniform platform of information exchange and a data model for all participants in the wind power station, and serves as a communication stack for mapping this information. This standard deploys common data classes of IEC 61850 to be corporate in SG. Its data object has been extended in the recent version [43].

\subsection{IEEE Standards}

\subsubsection{IEEE 1547}

IEC 1547 is a series of standards facilitating operation, control, monitoring, and integration of MG for utility networking for the provision of AS. The main drawback of this standard is the detail of establishing communication of MG with the supervisory level of the power system, i.e., TSO/DSO is unclear [43,44].

\subsubsection{IEEE 2030}

This standard is a series of standards clarifying the SG Interoperability Reference Model (SGIRM). In part seven it proposes specification of MG controllers and represents MG control system functional framework $[43,44]$.

\section{MG Communication Technologies}

In this section, to conform with the role of the hierarchical level of communication in MG, relevant technologies will be introduced. Technologies are partitioned into two groups: wired and wireless technologies.

\subsection{Wired Technologies}

Wired technologies, which can be used in MG, consist of PLC and ethernet at HAN and FAN level, Coaxial Cable and DSL in FAN level, and Fiber Optic in WAN level. Implementation of wired technologies costs more than wireless, especially in MG, since it is usually located in remote places, 
although they are not battery-dependent like wireless and are less affected by interference. However, the huge amount of interaction between sensors, actuators, meters, and controllers to provide smart MG makes it an inevitable technology. As our focus in this paper is wireless technologies, we just consider PLC, which is a legacy technology widely used for information communication in the power system for many years with low-cost implementation, as it uses transmission lines to interchange data by ultra-high frequency (UHF). This specification will be affected by the noise of other connected devices to the network. Ultra-Narrow Band PLC (UNBPLC), Narrow Band PLC (NBPLC), and Broad Band PLC (BBPLC), are three different categories of PLC deploying in MG. Wired technologies, characteristics, applications, and obstacles are represented in Table 4 [26,45].

\subsection{Wireless Technologies}

Trends to use wireless technologies in MG have been rising to reduce the complexity and cost of the system. Table 5 represents wireless technologies specification, namely data rates, coverage, application in MGMS, and merits and demerits of each technology. There are several wireless technologies, including Wireless Personal Area Network (WPAN), Wireless LAN (WLAN), cellular networks, Low Power Wide-Area Network (LPWAN), and Satellite Network within different standards applied in MG, of which noticeable ones will be discussed, following [21,26,45-49].

\subsubsection{ZigBee}

ZigBee is one of the widely used wireless technologies in HAN, especially in cases of the smart home because of low cost, energy consumption, and complexity working in the unlicensed band of $2.4 \mathrm{GHz}$. It is also one of the integrated communication technologies of metering equipment. ZigBee can provide tree, star, and mesh network topologies by Direct Sequence Spread Spectrum (DSSS) modulation. However, it suffers from common weak points of Industrial, Scientific, and Medical (ISM) license-free spectrum, which is at the risk of interference, although there are some approaches, such as the channel discovery algorithm based on Carrier Sense Multiple Access/Collision Avoidance (CSMA/CA) interference, that have been deployed to deal with this issue. It has been noted that in monitoring operation use cases, Zigbee is a prominent one.

\subsection{2. $\mathrm{WiFi}$}

WiFi is a wireless technology used for WLAN implementation within the IEEE 802.11 standard. It provides a frequency spectrum with a data rate of 2-600 Mbps and covers up to 100 meters distance. High penetration of WiFi as the Internet infrastructure makes it a good candidate for HAN and FAN applications.

\subsubsection{WiMAX}

This technology is one of the communication standards of the IEEE 802.16 series operating in licensed spectrum 2.5 or $3.5 \mathrm{GHz}$ and unlicensed spectrum of $5.8 \mathrm{GHz}$. Since there is along-distance coverage of licensed spectrum, it is appropriate for communication in HAN and FAN level in MG, especially in advanced AMI such as AMI for the supervision of measurement equipment in HAN. It can facilitate responsive load contribution in the provision of AS such as peak shaving or load shedding. It is reported that applying WiMAX in remote places requiring WiMAX tower installation, which will result in imposing an excess cost to the system. 
Table 4. Wired technologies specification and application in MG communication structure.

\begin{tabular}{|c|c|c|c|c|c|c|}
\hline Technologies & Standard/Protocols & Data Rate & Coverage & Application in MG Control & Advantages & Disadvantages \\
\hline Coaxial Cable & DOCSIS & 172 Mbps & $28 \mathrm{~km}$ & Smart appliances, AMI & $\begin{array}{l}\text { Low cost } \\
\boldsymbol{J} \text { Easy installation }\end{array}$ & $\begin{array}{l}\checkmark \text { Low scalability and bandwidth } \\
\checkmark \text { Susceptible to noise }\end{array}$ \\
\hline \multirow[t]{2}{*}{ Ethernet } & $802.3 X$ & 10 Mbps-10 Gbps & $100 \mathrm{~m}$ & Smart appliances, AMI & $\begin{array}{l}\checkmark \text { Well performance of capacity, } \\
\text { reliability, availability, and security }\end{array}$ & $\checkmark$ Complexity of installation \\
\hline & & & & & & $\begin{array}{l}\checkmark \text { Not perfect in real-time } \\
\text { communication }\end{array}$ \\
\hline \multirow{3}{*}{ DSL } & HDSL & $2 \mathrm{Mbps}$ & $3.6 \mathrm{~km}$ & \multirow{3}{*}{ AMI } & $\begin{array}{l}\checkmark \text { Cost effective because of existing } \\
\text { infrastructure }\end{array}$ & $\begin{array}{l}\checkmark \text { Possibility of degradation in data } \\
\text { quality }\end{array}$ \\
\hline & ADSL & 1-8 Mbps & $5 \mathrm{~km}$ & & $\begin{array}{l}\checkmark \text { Proven technology in residential } \\
\text { services }\end{array}$ & $\begin{array}{l}\checkmark \text { Out of power system management and } \\
\text { supervisory }\end{array}$ \\
\hline & VDSL & 15-100 Mbps & $1.5 \mathrm{~km}$ & & & \\
\hline \multirow{7}{*}{$\begin{array}{l}\text { Fiber } \\
\text { Optic }\end{array}$} & PON & $155 \mathrm{Mbps}-2.5 \mathrm{Gbps}$ & $60 \mathrm{~km}$ & \multirow{7}{*}{$\begin{array}{l}\text { AMI, } \\
\text { DMS }\end{array}$} & $\begin{array}{l}\checkmark \text { Not affected by noise and } \\
\text { electromagnetic interferences }\end{array}$ & $\sqrt{ }$ High Cost \\
\hline & $\mathrm{AON}$ & $100 \mathrm{Mbps}$ & $10 \mathrm{~km}$ & & \multirow[t]{6}{*}{$\begin{array}{l}\text { JWell performance of Capacity, } \\
\text { Reliability, Availability, Security, and } \\
\text { Latency }\end{array}$} & \multirow[t]{6}{*}{$\checkmark$ Low Scalability } \\
\hline & BPON & 155-622 Mbps & $20-60 \mathrm{~km}$ & & & \\
\hline & GPON & 155 Mbps-2.448 Gpbs & $20 \mathrm{~km}$ & & & \\
\hline & EPON & $1 \mathrm{Gbps}$ & $20 \mathrm{~km}$ & & & \\
\hline & SONET/SDH & $10 \mathrm{Gbps}$ & $100 \mathrm{~km}$ & & & \\
\hline & WDM & $40 \mathrm{Gbps}$ & $100 \mathrm{~km}$ & & & \\
\hline \multirow[t]{3}{*}{ PLC } & UNBPLC & $100 \mathrm{bpc}$ & $150 \mathrm{~km}$ & \multirow[t]{3}{*}{$\begin{array}{l}\text { Smart appliances, } \\
\text { AMI, EMS, DMS }\end{array}$} & \multirow[t]{3}{*}{$\begin{array}{l}\checkmark \text { Convenience and cost effective because } \\
\text { of no need separatedinfrastructure from } \\
\text { power grid }\end{array}$} & \multirow[t]{3}{*}{$\begin{array}{l}\checkmark \text { Subjected by interference of power } \\
\text { grid noise or weather conditions }\end{array}$} \\
\hline & NBPLC & $10-500 \mathrm{kbps}$ & $150 \mathrm{~km}$ & & & \\
\hline & BBPLC & 10-200 Mbps & $1.5 \mathrm{~km}$ & & & \\
\hline
\end{tabular}


Table 5. Wireless technologies specification and application in MG communication structure.

\begin{tabular}{|c|c|c|c|c|c|c|}
\hline Technologies & Standard/Protocols & Data Rate & Coverage & Application in MGMS & Advantages & Disadvantages \\
\hline \multirow{5}{*}{ WPAN } & Z-Wave & $40 \mathrm{Kbps}$ & $30 \mathrm{~m}$ & $\begin{array}{l}\text { Smart Appliances } \\
\text { HEMS }\end{array}$ & $\begin{array}{l}\checkmark \text { No interference } \\
\checkmark \text { Free bandwidth } \\
\mathcal{J} \text { Mesh Connectivity }\end{array}$ & $\begin{array}{l}\checkmark \text { Low data rate } \\
\text { Shigh power consumption }\end{array}$ \\
\hline & Bluetooth & 1-2 Mbps & $15-30 \mathrm{~m}$ & $\begin{array}{l}\text { Smart Appliances } \\
\text { HEMS }\end{array}$ & $\begin{array}{l}\text { J Free bandwidth } \\
\text { JLow power consumption } \\
\mathcal{V} \text { High Data Rate }\end{array}$ & $\begin{array}{l}\text { J Very short range } \\
\text { J Subjected by noise } \\
\text { /Unsafe }\end{array}$ \\
\hline & ZigBee & $250 \mathrm{Kbps}$ & $100 \mathrm{~m}$ & $\begin{array}{l}\text { HEMS } \\
\text { EVs }\end{array}$ & $\begin{array}{l}\text { Low cost } \\
\checkmark \text { Low Power Consumption }\end{array}$ & $\begin{array}{l}\text { Jow data rate } \\
\text { VShort Range } \\
\text { VInterference }\end{array}$ \\
\hline & WirelessHART & $115 \mathrm{Kbps}$ & $200 \mathrm{~m}$ & $\begin{array}{l}\text { HEMS } \\
\text { Smart meters }\end{array}$ & $\begin{array}{l}\text { SScalable } \\
\checkmark \text { Backward compatible }\end{array}$ & $\begin{array}{l}\text { Low data rate } \\
\text { SShort range } \\
\text { SInterference }\end{array}$ \\
\hline & $\begin{array}{l}\text { ZigBee Pro } \\
\text { (inter-WPAN) }\end{array}$ & $250 \mathrm{Kbps}$ & $1.6 \mathrm{~km}$ & $\begin{array}{l}\text { V2G, } \\
\text { AMI }\end{array}$ & $\begin{array}{l}\text { JMesh } \\
\text { Connectivity }\end{array}$ & $\begin{array}{l}\text { Low data rate } \\
\text { VInterference }\end{array}$ \\
\hline WLAN & WiFi(802.11X) & 2-600 Mbps & $100 \mathrm{~m}$ & $\begin{array}{l}\text { Smart Appliances } \\
\text { V2G } \\
\text { AMI }\end{array}$ & $\begin{array}{l}\mathcal{} \text { Low cost } \\
\checkmark \text { High Data rate } \\
\checkmark \text { Wide adoption } \\
\end{array}$ & $\begin{array}{l}\text { Short range } \\
\text { JInterference } \\
\text { VLow Security }\end{array}$ \\
\hline \multirow{7}{*}{$\begin{array}{l}\text { Cellular } \\
\text { Network } \\
\text { Communication }\end{array}$} & WiMAX(802.16) & $75 \mathrm{Mbps}$ & $50 \mathrm{~km}$ & $\begin{array}{l}\text { DMS } \\
\text { EMS } \\
\text { AMI } \\
\text { DR }\end{array}$ & $\begin{array}{l}\text { VHigh Data rate } \\
\text { /QoS Provisioning } \\
\text { /Scalability } \\
\text { } / \text { Low Latency }\end{array}$ & $\begin{array}{l}\text { VNot widespread use } \\
\checkmark \text { Dedicated Infrastructure } \\
\checkmark \checkmark \text { Limited Access to licensed spectrum }\end{array}$ \\
\hline & 2G (GSM) & 14.4 Kbps & $1-10 \mathrm{~km}$ & & $\begin{array}{l}\mathcal{J} \text { Existing infrastructure and service } \\
\text { models }\end{array}$ & $\begin{array}{l}\text { JOriented for human broadband } \\
\text { applications }\end{array}$ \\
\hline & 2.5G (GPRS) & 144 Kbps & $1-10 \mathrm{~km}$ & & $\checkmark$ Ubiquitous coverage & \\
\hline & $3 \mathrm{G}$ & $2 \mathrm{Mbps}$ & $1-10 \mathrm{~km}$ & & $\checkmark$ Low latency & $\checkmark$ Monthly recurring charges \\
\hline & $3.5 \mathrm{G}$ & $14 \mathrm{Mbps}$ & $0-5 \mathrm{~km}$ & & $\checkmark$ High data rate & $\begin{array}{l}\checkmark \text { Not currently support for } \\
\text { mission-critical applications }\end{array}$ \\
\hline & $4 \mathrm{G}$ & $1 \mathrm{Gbps}$ & $50 \mathrm{~km}$ & & $\checkmark$ QoS Provisioning & \\
\hline & $\begin{array}{l}5 \mathrm{G} \\
\text { SIFOX }\end{array}$ & $\begin{array}{l}>1 \mathrm{Gbps} \\
100 \mathrm{bps}\end{array}$ & $\begin{array}{l}50 \mathrm{~km} \\
\text { Urban Area: } 3-10 \mathrm{~km} \\
\text { Rural Area: } 30-50 \mathrm{~km}\end{array}$ & $\begin{array}{l}\text { AMI } \\
\text { DMS }\end{array}$ & $\checkmark$ Low power consumption & $\checkmark$ Low data range \\
\hline LPWAN & LoRa & $\begin{array}{l}\text { LoRa modulation: } 0.3-37.5 \mathrm{Kbps} \\
\text { LoRaWAN: } 50 \mathrm{Kbps}\end{array}$ & $\begin{array}{l}\text { Urban Area: } 2-5 \mathrm{~km} \\
\text { Rural Area: } 10-15 \mathrm{~km}\end{array}$ & & $\checkmark$ better data range (LoRaWAN) & \\
\hline \multirow{3}{*}{$\begin{array}{l}\text { Satellite } \\
\text { Network }\end{array}$} & LEO & Iridium: 2.4-28 Kbps & $100-6000 \mathrm{~km}$ & DMS, AMI & $\checkmark$ Wide-area coverage & $\sqrt{ }$ High cost \\
\hline & MEO & Inmarsat-B: 9.6-128 Kbps & & & $\sqrt{ }$ High reliability & $\checkmark$ High Latency \\
\hline & GEO & BGAN: 1 Mbps & & & & \\
\hline
\end{tabular}




\subsection{4. $5 \mathrm{G}$}

Cellular networks such as GSM, GPRS, 3G, 3.5G, 4G, and 5G have high data rate communication and bandwidth. This characteristic facilitates the transfer of a huge amount of data. Therefore, these technologies can be used in applications such as interchange among smart meters, MG control center, and supervisory level of the main grid, i.e., DMS in WAN environments. High-cost licensed spectrum and the uncertainty of stable connectivity in severe weather conditions are drawbacks of this technology, although cellular technologies could defeat interference and security issues of free bands by applying licensed bands. Cellular communication, which was initially introduced in the 1980s based on analogue signal communication, has been developed to IP-based communication such as 4G and 5G for increasing bandwidth and sustaining real-time communication. 4G, which is called Long-Term Evolution-Advanced (LTE-A), increased the data rate of its predecessor generation, i.e., $3 \mathrm{G}$ from the range of 2-14 Mbps to the range of $100 \mathrm{Mbps}-1 \mathrm{Gbps}$ as well as latency and improvement of infrastructure energy consumption. Meanwhile, noticeable advancement in this technology is happening by the introduction of 5G to facilitate IoT application penetration in MGMS. The high performance of $5 \mathrm{G}$ has three characteristics, including Millimeter-Wave (mm-Wave), Multiple-Input Multiple-Output (MIMO), and ultra-dense cellular network. This technology brings benefits such as lower latency, higher bandwidth, a larger number of participants and nodes in MGMS, higher security, and so on. Enhanced Mobile Broadband (eMBB), Ultra-reliable and Low-latency Communications (uRLLC), and Massive Machine Type Communications (mMTC) are services offered by $5 \mathrm{G}$ as The International Telecommunication Union (ITU) determined. While an eMBB service is a response to individual aspects of the world digitalization communication requirements, uRLLC and mMTC are related to higher scales of this trend, including industry and society aspects, respectively. Hence eMBB provides higher bandwidths for applications such as 3D and High-Definition (HD) Video and Virtual Reality (VR). This ultra-bandwidth can reach to $10 \mathrm{Gbps}$. On the other hand, uRLLC offers low latency limited to $1 \mathrm{~ms}$ for time and reliability sensitive applications such as driverless cars and industrial automation. Finally, mMTC represents the number of connected devices up to 1 million $/ \mathrm{km}^{2}$, facilitates the implementation of smart homes and smart cities [50].

\subsubsection{LPWAN}

This technology was introduced to provide equilibrium between energy consumption and data rate in WAN. Cellular networks have been widely used to transmit high data rates in WAN but with high energy consumption. LPWAN could defeat this weak point of a cellular network by introducing SIGFOX and LoRa. These technologies have been applied to a star topology, which will result in the simplicity of the system and less power consumption. LoRa technology is divided into two subsets, including LoRa modulation and LoRaWAN. LoRa is a physical layer protocol using ISM bandwidth modulation. Despite Frequency Shifting Key (FSK) used by legacy wireless protocols, LoRa applies Chirp Spread Spectrum (CSS) brought by a higher data rate for LoRa. While LoRa modulation is a physical layer protocol, LoRaWAN contains the MAC layer as well as the physical layer and improves data rate concerning power consumption [51-54].

\subsubsection{Satellite Technology}

Satellite technology is a solution for MG communication in remote places where cellular or other wireless technologies are not accessible. Furthermore, they can be applied as a redundant path for creating backup communication. There are three different satellite technologies, including Low Earth Orbits (LEO), Medium Earth Orbit (MEO), and Geostationary Earth Orbits (GEO). Table 5 shows the characteristics of satellite technologies. The major disadvantages of satellite technologies are high expense and high latency. However, LEO and MEO areas are being developed to improve latency and bandwidth. More service providers represent GEO, including Inmarsat, BGAN, Swift, and MPDS while just NEW ICO offers MEO. Iridium and Globalstar are operators of LEO [55,56]. 


\section{Wireless Technologies Roadmap and Future Trends for MG}

MG is one of the key elements of the developed power grid system, which is being widely used because of the aforementioned merits. Regarding wireless specification correspondence of MG remote and independent specification, in the previous section, features of wireless technologies and applications in each part of the hierarchical supervisory of MG are discussed. Table 6 depicts how the literature considers applying wireless in MG. As can be seen, the literature proves wireless communication benefits in MG according to different goals and examination methods. We classified them into control, standard, and technology-based categories. This table reveals a new approach to the role of MG in the power system, as an active element is under trial and error test by using new enhancements of wireless technologies [52,57]. Concerning countless merits of wireless technologies application in MG, it is necessary to determine a roadmap clarifying the future path of this enhancement. To provide a roadmap for applying wireless technologies in MGMS, we should consider the following aspects.

\subsection{MGMS Structure Development}

New wireless technologies should consider communication specification requirements of MG application such as bandwidth, latency, and security. To provide a mechanism for applying wireless in MG, we require a definition of unified information exchange and standard. The unified model should be flexible to apply in the different control structures of MG depending on the extent, application, and geographical location of MG. As discussed before, MG can be centralized or decentralized. One of the promising strategies in distributed control of MG is MAS, which facilitates control of MG and assists the SG concept approach in reality by accommodating self-healing characteristics for the power grid [7,58-61]. In the MAS environment, every element of MG can interact and cooperate with other elements intelligently to achieve power system global objectives, as can be seen in Figure 4 . In this case, although there is no "one size fits all" approach, robust technologies such as 5G can be deployed in two control architectures. Central control of MG can derive active power and reactive power of load information and control generation portion of each power resource in MG by applying $5 \mathrm{G}$ communication and cloud computing at the edge. It is also possible for 5G employment in decentralized MG control based on droop control power, which needs real-time reference control signals, large distance coverage, and security [62]. As well as the independent grid characteristic of MG, there are new aspects in the smartization of MG, making it an integrated part of the public grid, which is the main hypothesis of this paper. MG as an AS of the main grid is one of the aspects, which will be an incentive for penetration extension of MG as it provides profit for owners. Such aspects require the contribution of technologies in MG such as V2G, smart inverter, etc. Wireless technology is a good candidate as a communication infrastructure of these technologies [63]. AS provision of the main grid, including frequency regulation, voltage control, and black-start aid by MG needs its communication characteristics, especially time constraints, which can be met by $5 \mathrm{G} \mathrm{mm}$-Wave characteristics offering fast, reliable, and robust interacting [64-67].

\subsection{MGMS Communication Standard Development}

The development of relevant standards introduced in Section 3 is a prerequisite to meet wireless technologies in MGMS. For instance, WirelessHART in [68] was noticed facilitating IEC 61850 in the distributed generation sector. A communication stack of IEC 61850, which is the OSI model, is changed and information model and exchange mapped to the wirelessHART protocol. However, it could not meet time limitation requirements of the standard, and the authors referred to solving this weak point to future work. This practice shows that since the most serving MGMS communication standard is IEC 61850, the communication stack of this standard should consider technology developments of wireless communication concerning their coordination with new trends in MGMS. 
Table 6. Classification of wireless-based MG studies.

\begin{tabular}{|c|c|c|c|c|c|c|}
\hline Classification & Ref & Wireless Technology & $\begin{array}{l}\text { Standard/Protocol } \\
\text { Deployment }\end{array}$ & Qualification & Tools & Objectives \\
\hline \multirow{6}{*}{ Standard-based } & [69] & WLAN & IEC 61850 & $\begin{array}{l}\text { JGOOSE messages performance, } \\
\text { time delay and throughput } \\
\text { requirements, as well as the distance } \\
\text { between DAS and DER }\end{array}$ & OPNET & $\begin{array}{l}\text { JCommunication systems between } \\
\text { IEC 61850-based distribution } \\
\text { substation and DER }\end{array}$ \\
\hline & [68] & WirelessHART & IEC 61850 & 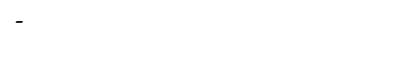 & OPNET & $\begin{array}{l}\checkmark \text { Cabling and installation cost } \\
\text { reduction,Portability }\end{array}$ \\
\hline & [70] & $\begin{array}{l}\text { WiFi IEEE } \\
\text { 802.11.n.Z-wave }\end{array}$ & IEC 61850 & $\begin{array}{l}\checkmark \text { Latency, Availability, Time } \\
\text { synchronization accuracy, Reliability }\end{array}$ & Real test & $\begin{array}{l}\checkmark \text { Automation of MG using } \\
\text { heterogeneous communication }\end{array}$ \\
\hline & [71] & WiFi IEEE 802.11.g & IEC 61850 & $\begin{array}{l}\text { Effect of communication distance, } \\
\text { Delay in burst background Traffic }\end{array}$ & OPNET & $\checkmark$ Smart MG based on IEC 61850 \\
\hline & [72] & WiFi IEEE 802.11.g, & IEC 61850 & $\checkmark$ Average delay & Riverbed modeler & $\begin{array}{l}\checkmark \text { Smart home and smart meters } \\
\text { based on IEC } 61850\end{array}$ \\
\hline & & $\begin{array}{l}\text { WiFi IEEE 802.11.n, } \\
\text { WiMax 802.16 }\end{array}$ & & $\checkmark$ Packet loss per second & & \\
\hline \multirow{8}{*}{ Control-based } & [73] & Cellular Network & - & $\begin{array}{l}\text { Data rates, ranges, and capacity of } \\
\text { the cognitive radio }\end{array}$ & - & $\begin{array}{l}\checkmark \text { Data service energy center by } \\
\text { wireless access to AMI }\end{array}$ \\
\hline & [74] & WiMAX & - & $\checkmark$ Bit error rate & MATLAB & $\checkmark$ Real-time protection, Reliability \\
\hline & [75] & $\begin{array}{l}\text { wireless community } \\
\text { mesh network }\end{array}$ & - & $\begin{array}{l}\checkmark \text { Impact of the time-varying } \\
\text { wireless communication delay on } \\
\text { the performance of distributed } \\
\text { power inverters }\end{array}$ & MATLAB & $\checkmark$ Load Sharing \\
\hline & {$[76]$} & - & - & $\begin{array}{l}\checkmark \text { Maintains the magnitude of the } \\
\text { voltage and frequency within the } \\
\text { acceptable limits (EN 50160) }\end{array}$ & - & $\checkmark$ Wireless EMS \\
\hline & [77] & $\begin{array}{l}\text { IEEE } 802.11 \text { MAC } \\
\text { standard }\end{array}$ & - & $\begin{array}{l}\checkmark \text { MAS-based decentralized MG } \\
\text { control }\end{array}$ & NS-2 & $\begin{array}{l}\checkmark \text { Information accuracy for } \\
\text { multi-agent coordination }\end{array}$ \\
\hline & [18] & WiFi, WiMAX, ZigBee & - & $\begin{array}{l}\checkmark \text { Algorithm of control and energy } \\
\text { management for MG }\end{array}$ & MATLAB & $\checkmark$ Real-Time control of MG \\
\hline & [78] & - & & $\checkmark$ Power and control architecture & & $\checkmark$ Increase RER penetration in MG \\
\hline & [79] & WiFi & Modbus & $\begin{array}{l}\checkmark \text { Time delay, Transmission error } \\
\text { rate, Coverage }\end{array}$ & Laboratory Testbed & $\begin{array}{l}\checkmark \text { Energy management, Monitoring, } \\
\text { and control }\end{array}$ \\
\hline \multirow{3}{*}{ Communication Technology-based } & [80] & ZigBee & - & $\begin{array}{l}\checkmark \text { Defining required data to be } \\
\text { transferred and a suitable coding }\end{array}$ & PSCAD & $\begin{array}{l}\checkmark \text { Data management scheme to } \\
\text { overcome Low data transfer rate of } \\
\text { ZigBee }\end{array}$ \\
\hline & [52] & LoRaWAN & - & $\begin{array}{l}\checkmark \text { Time-on-air, duty cycle, and packet } \\
\text { delivery ratio }\end{array}$ & field test & $\begin{array}{l}\text { SProvide multihop solution for P2P } \\
\text { (Peer to Peer) communicate between } \\
\text { LoRa devices to prove LoRa as } \\
\text { communication method in regional } \\
\text { MG }\end{array}$ \\
\hline & [57] & $5 \mathrm{G}$ & OPC UA & - & $\begin{array}{l}\text { Functional Mockup Interface } \\
\text { (FMI) for modeling prosumers }\end{array}$ & $\checkmark$ multi-MG EMS \\
\hline
\end{tabular}




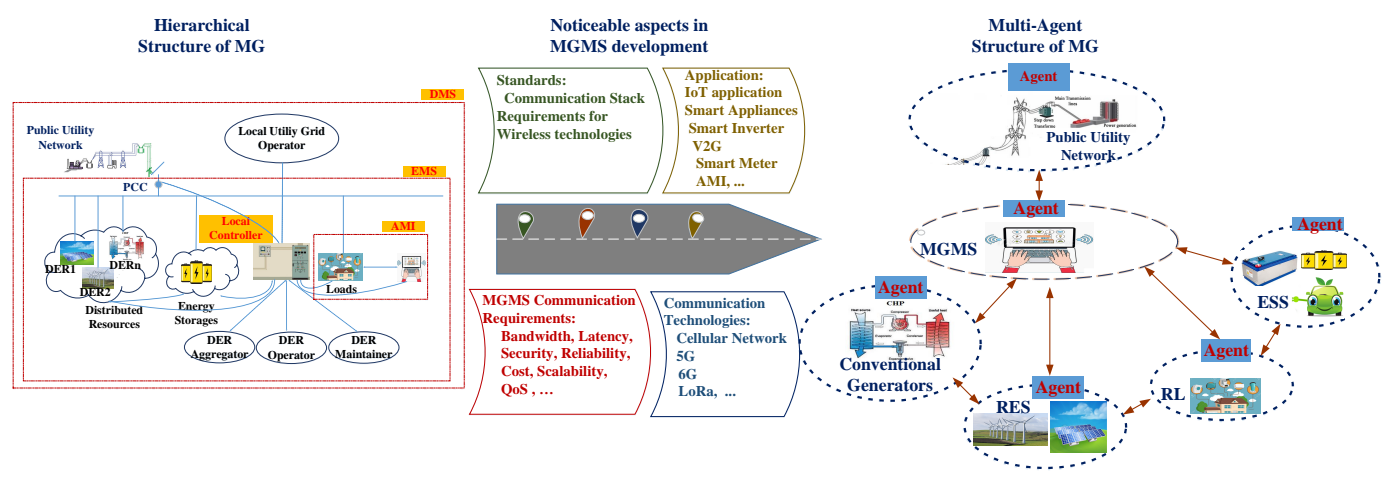

Figure 4. Basis of MGMS development.

\subsection{MGMS IoT Integrated}

MGMS was also revolutionized by the high penetration of IoT devices, especially in HEMS, which motivates the effective contribution of MG in DR through AMI and smart meters. This enhancement provides an infrastructure to schedule each home appliance inside MG to participate in DR resulting in a rocketing number of nodes. 5G technology based on MIMO characteristics can support communication with this number of nodes. LoRaWAN according to its lower power consumption, high data rate, and secure communication is another appropriate candidate for smart monitoring [81,82].

Figure 4 depicts an effective roadmap for applying wireless technology elements in MGMS, including communication specification, application, standards, and new technologies' requirements of MGMS.

\section{Future Work}

During an evolution towards MAS and multi-MG, emerging system interconnection has increased the operation and maintenance of communication infrastructure. Wireless communication enhancement with the introduction of new approaches such as $5 \mathrm{G}$ has been providing a solution to tackle this problematic issue by conservation cost of the system through network slicing and cloud concepts. Future work will conduct a determination of MGMS service-level requirements mapping into a service-driven 5G network and in a holistic approach for cloud-based communication structures for multi-MG and MAS investigation with wireless communication and IoT assistance.

\section{Conclusions}

MG is a solution, which facilitates SG implementation by using RER along with the control and management of loads and sources, which overcomes the intermittent nature of RER. Therefore, the management of MG is a key element that requires a robust communication infrastructure. This paper also revealed the role of MG in the power system by racketing its penetration changes to active elements, which offers AS to a utility public network. Because of its simplicity, affordability, and superb performance of wireless communication, especially in remote places, we noticed communication technologies and their characteristics in this paper in a way that summarized and reviewed applying them in different levels of MGMS as a prominent contribution of this paper, which has been ignored in recent studies. According to the MG diversity of applications, there are different control and management scenarios. Investigation of a holistic wireless employment roadmap in MGMS was another achievement of this study, which covers different control methodology scenarios and correspondence of new enhancements in wireless technology characteristics such as 5G and LoRa with new requirements of MG as an active element of the power system. This roadmap highlighted wireless enhancement application in the implementation of the developed structure of MGMS, including MAS, and higher-aspect multi-MG structure of SG. Mapping service-level requirements of these developed 
MGMS to network slicing and cloud concepts through application of recent wireless technologies introduced as a new horizon of this research area.

Author Contributions: Conceptualization, L.T. and H.Y.; Data curation, L.T. and H.Y.; Writing—original draft preparation, L.T., H.Y. and M.J.P.; Writing—review and editing, L.T., H.Y. and M.J.P.; Supervision, L.T. and H.Y. All authors have read and agreed to the published version of the manuscript.

Funding: This work was supported by the National Research Foundation of Korea (NRF) grant funded by the Korea government (MSIT) (No. 2019M3F2A1073179) and by Korea Electric Power Corporation (Grant number: R17XA05-66).

Conflicts of Interest: The authors declare no conflict of interest.

\section{Abbreviations}

The following abbreviations are used in this manuscript:

AMI Advanced Metering Interface

AS Ancillary Services

BBPLC Broad Band PLC

CSS Chirp Spread Spectrum

CT Current Transformer

DER Distributed Energy Resources

DMS Distribution Management System

DR Demand Response

DSO Distribution System Operator

DSSS Direct Sequence Spread Spectrum

eMBB Enhanced Mobile Broadband

EMS Energy Management System

ESS Energy Storage System

EV Electric Vehicle

5G Fifth-Generation

FMI Functional Mockup Interface

FSK Frequency Shifting Key

GEO Geostationary Earth Orbits

GOOSE Generic Object-Oriented Substation Event

GSM Global System for Mobile

FAN Field Area Network

HAN Home Area Network

HD High-Definition

HEMS Home Energy Management System

IEC International Electrotechnical Commission

IED Intelligent Electronic Devices

IEEE Institute of Electrical and Electronics Engineers

IoT Internet of Things

ISM Industrial, Scientific, and Medical

ITU International Telecommunication Union

LAN Local Area Network

LEO Low Earth Orbits

LPWAN Low Power WAN

LTE Long-Term Evolution

MAS Multi-Agent System

MEO Medium Earth Orbit

MG Micro-Grid

MGMS Micro-Grid Management System

MIMO Multiple-Input Multiple-Output

MMS Manufacturing Message Specification

mMTC Massive Machine Type Communications

mm-Wave Millimeter-Wave

NBPLC Narrow Band PLC

OSI Open System Interaction

PCC Point of Common Coupling

PLC Power Line Carrier

PMU Phasor Measurements Units

P2P Peer to Peer 


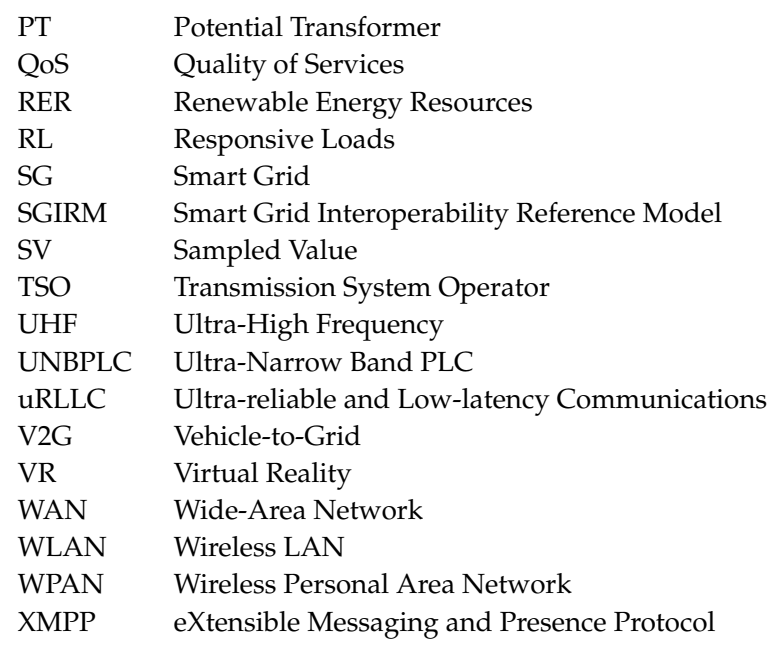

\section{References}

1. Vera, G.; Yimy, E.; Dufo-López, R.; Bernal-Agustín, J.L. Energy management in microgrids with renewable energy sources: A literature review. Appl. Sci. 2019, 9, 3854. [CrossRef]

2. Lasseter, R.H. Smart Distribution: Coupled Microgrids. Proc. IEEE 2011, 99, 1074-1082. [CrossRef]

3. IEEE Standard for the Specification of Microgrid Controllers; IEEE Std 2030.7; IEEE Standards Association: Piscataway, NJ, USA, 2018.

4. Piagi, P.; Lasseter, R.H. Autonomous control of microgrids. In Proceedings of the IEEE Power Engineering Society General Meeting, Montreal, QC, Canada, 18-22 June 2006; p. 8.

5. Jiang, Z.; Yu, X. Power electronics interfaces for hybrid DC and AC-linked microgrids. In Proceedings of the IEEE 6th International Power Electronics and Motion Control Conference, Wuhan, China, 17-20 May 2009; pp. 730-736.

6. Wu, D.; Dragicevic, T.; Vasquez, J.C.; Guerrero, J.M.; Guan, Y. Secondary coordinated control of islanded microgrids based on consensus algorithms. In Proceedings of the IEEE Energy Conversion Congress and Exposition (ECCE), Pittsburgh, PA, USA, 14-18 September 2014; pp. 4290-4297.

7. Han, Y.; Zhang, K.; Li, H.; Coelho, E.A.A.; Guerrero, J.M. MAS-based distributed coordinated control and optimization in microgrid and microgrid clusters: A comprehensive overview. IEEE Trans. Power Electron. 2017, 33, 6488-6508. [CrossRef]

8. Zaidi, A.A.; Kupzog, F. Microgrid automation-a self-configuring approach. In Proceedings of the IEEE International Multitopic Conference, Karachi, Pakistan, 23-24 December 2008; pp. 565-570.

9. Jiang, T.; Costa, L.M.; Siebert, N.; Tordjman, P. Automated microgrid control systems. IET Cired Open Access Proc. J. 2017, 961-964. [CrossRef]

10. Venkata, S.M.; Shahidehpour, M. Microgrid controllers: The brain, heart, \& soul of microgrid automation. IEEE Power Energy Mag. 2017, 15, 16-22.

11. Ustun, T.S.; Ozansoy, C.; Zayegh, A. Simulation of communication infrastructure of a centralized microgrid protection system based on IEC 61850-7-420. In Proceedings of the IEEE Third International Conference on Smart Grid Communications (SmartGridComm), Tainan, Taiwan, 5-8 November 2012; pp. $492-497$.

12. Mao, M.; Mei, F.; Jin, P.; Chang, L. Application of IEC61850 in energy management system for microgrids. In Proceedings of the IEEE 5th International Symposium on Power Electronics for Distributed Generation Systems (PEDG), Galway, Ireland, 24-27 June 2014; pp. 1-5.

13. Yoo, B.; Yang, H.S.; Yang, S.; Jeong, Y.S.; Kim, W.Y. CAN to IEC 61850 for Microgrid system. In Proceedings of the IEEE International Conference on Advanced Power System Automation and Protection, Beijing, China, 16-20 October 2011; Volume 2, pp. 1219-1224.

14. Zaheeruddin; Manas, M. Renewable energy management through microgrid central controller design: An approach to integrate solar, wind and biomass with battery. Elsevier Energy Rep. 2015, 1, 156-163.

15. Palizban, O.; Kauhaniemi, K.; Guerrero, J.M. Microgrids in active network management-part II: System operation, power quality and protection. Elsevier Renew. Sustain. Energy Rev. 2014, 36, 440-451. [CrossRef] 
16. Chavan, M.P.; Devi, R.J. Survey of Communication System for DG's and Microgrid in Electrical Power Grid. Int. Res. J. Eng. Technol. 2016, 3, 1155-1164.

17. Islam, M.; Lee, H.H. Microgrid communication network with combined technology. In Proceedings of the IEEE 5th International Conference on Informatics, Electronics and Vision (ICIEV), Dhaka, Bangladesh, 13-14 May 2016; pp. 423-427.

18. Elkhorchani, H.; Grayaa, K. Smart micro Grid power with wireless communication architecture. In Proceedings of the IEEE International Conference on Electrical Sciences and Technologies in Maghreb (CISTEM), Tunis, Tunisia, 3-6 November 2014; pp. 1-10.

19. Weimer, J.; Xu, Y.; Fischione, C.; Johansson, K.H.; Ljungberg, P.; Donovan, C.; Sutor, A.; Fahlén, L.E. A virtual laboratory for micro-grid information and communication infrastructures. In Proceedings of the 3rd IEEE PES Innovative Smart Grid Technologies Europe (ISGT Europe), Berlin, Germany, 14-17 October 2012; pp. 1-6.

20. Marzal, S.; Salas, R.; González-Medina, R.; Garcerá, G.; Figueres, E. Current challenges and future trends in the field of communication architectures for microgrids. Elsevier Renew. Sustain. Energy Rev. 2018, 82, 3610-3622. [CrossRef]

21. Safdar, S.; Hamdaoui, B.; Cotilla-Sanchez, E.; Guizani, M. A survey on communication infrastructure for micro-grids. In Proceedings of the IEEE 9th International Wireless Communications and Mobile Computing Conference (IWCMC), Sardinia, Italy, 1-5 July 2013; pp. 545-550.

22. Mariam, L.; Basu, M.; Conlon, M.F. A review of existing microgrid architectures. Hindawi J. Eng. 2013, 2013, 937614. [CrossRef]

23. Bani-Ahmed, A.; Weber, L.; Nasiri, A.; Hosseini, H. Microgrid communications: State of the art and future trends. In Proceedings of the IEEE 2014 International Conference on Renewable Energy Research and Application (ICRERA), Milwaukee, WI, USA, 19-22 October 2014; pp. 780-785.

24. Mavrokefalidis, C.; Ampeliotis, D.; Berberidis, K. A study of the communication needs in micro-grid systems. In Proceedings of the XXXIInd General Assembly and Scientific Symposium of the International Union of Radio Science (URSI GASS), Montreal, QC, Canada, 19-26 August 2017; pp. 1-4.

25. Mai, T.; Haque, A.; Vo, T.; Nguyen, P.; Pham, M.C. Development of ICT infrastructure for Physical LV Microgrids. In Proceedings of the IEEE International Conference on Environment and Electrical Engineering and 2018 IEEE Industrial and Commercial Power Systems Europe (EEEIC/I\&CPS Europe), Palermo, Italy, 12-15 June 2018; pp. 1-6.

26. Arbab-Zavar, B.; Palacios-Garcia, E.J.; Vasquez, J.C.; Guerrero, J.M. Smart Inverters for Microgrid Applications: A Review. Energies 2019, 12, 840. [CrossRef]

27. Amicarelli, E.; Tran, Q.T.; Bacha, S. Multi-agent system for day-ahead energy management of microgrid. In Proceedings of the IEEE 2016 18th European Conference on Power Electronics and Applications (EPE'16 ECCE Europe), Karlsruhe, Germany, 5-9 September 2016; pp. 1-10.

28. Hossain, E.; Han, Z.; Poor, H.V. Smart Grid Communications and Networking; Cambridge University Press: Cambridge, UK, 2012.

29. Merabet, G.H.; Essaaidi, M.; Talei, H.; Abid, M.R.; Khalil, N.; Madkour, M.; Benhaddou, D. Applications of multi-agent systems in smart grids: A survey. In Proceedings of the IEEE 2014 International Conference on Multimedia Computing and Systems (ICMCS), Marrakech, Morocco, 14-16 April 2014; pp. 1088-1094.

30. Howell, S.; Rezgui, Y.; Hippolyte, J.L.; Jayan, B.; Li, H. Towards the next generation of smart grids: Semantic and holonic multi-agent management of distributed energy resources. Elsevier Renew. Sustain. Energy Rev. 2017, 77, 193-214. [CrossRef]

31. Priyadarshana, H.; Sandaru, M.K.; Hemapala, K.; Wijayapala, W. A review on Multi-Agent system based energy management systems for micro grids. AIMS Energy 2019, 7, 924. [CrossRef]

32. Karimi, H.; Jadid, S. Optimal energy management for multi-microgrid considering demand response programs: A stochastic multi-objective framework. Energy 2020, 195, 116992. [CrossRef]

33. Kuzlu, M.; Pipattanasomporn, M.; Rahman, S. Communication network requirements for major smart grid applications in HAN, NAN, and WAN. Elsevier Comput. Netw. 2014, 67, 74-88. [CrossRef]

34. Basic Communication Structure-Distributed Energy Resources Logical Nodes; IEC61850-7-420; IEC: Geneva, Switzerland, 2009.

35. Specific Communication Service Mapping (SCSM)_Mapping to Extensible Messaging Presence Protocol (XMPP); IEC61850-8-2; IEC: Geneva, Switzerland, 2018. 
36. Object Models for Power Converters in Distributed Energy Resources (DER) Systems; IEC61850-90-7; IEC: Geneva, Switzerland, 2013.

37. Wide Area Network Engineering Guidelines; IEC61850-90-12; IEC: Geneva, Switzerland, 2015.

38. Communications for Monitoring and Control of Wind Power Plants-Information Models; IEC 61400-25-2; IEC: Geneva, Switzerland, 2015.

39. IEEE Guide for Monitoring, Information Exchange, and Control of Distributed Resources Interconnected with Electric Power Systems; IEEE Std 1547.3-2007; IEEE Standards Association: Piscataway, NJ, USA, 2007.

40. IEEE Guide for Smart Grid Interoperability of Energy Technology and Information Technology Operation with the Electric Power System (EPS), End-Use Applications, and Loads; IEEE Std 2030-2011; IEEE Standards Association: Piscataway, NJ, USA, 2011.

41. Tightiz, L.; Yang, H. Survey of IEC61850 M2M Interface based on IoT Protocols in Smart Grid Environment. In Proceedings of the Korea Institute Of Communication Sciences (KICS) Winter Conference, YongPyung Resort, Korea, 23-25 February 2019; Volume 1; pp. 382-385.

42. Jindal, A.; Marnerides, A.K.; Gouglidis, A.; Mauthe, A.; Hutchison, D. Communication standards for distributed renewable energy sources integration in future electricity distribution networks. In Proceedings of the IEEE International Conference on Acoustics, Speech and Signal Processing (ICASSP), Brighton, UK, 12-17 May 2019; pp. 8390-8393.

43. Sato, T.; Kammen, D.M.; Duan, B.; Macuha, M.; Zhou, Z.; Wu, J.; Tariq, M.; Asfaw, S.A. Smart Grid Standards: Specifications, Requirements, and Technologies; John Wiley \& Sons: Hoboken, NJ, USA, 2015.

44. Basso, T.; DeBlasio, R. IEEE Smart Grid Series of Standards IEEE 2030 (Interoperability) and IEEE 1547 (Interconnection) Status; Technical Report; National Renewable Energy Lab. (NREL): Golden, CO, USA, 2012.

45. Gungor, V.C.; Sahin, D.; Kocak, T.; Ergut, S.; Buccella, C.; Cecati, C.; Hancke, G.P. Smart grid technologies: Communication technologies and standards. IEEE Trans. Ind. Inform. 2011, 7, 529-539. [CrossRef]

46. Bouhafs, F.; Mackay, M.; Merabti, M. Communication Challenges and Solutions in the Smart Grid; Springer: Berlin, Germany, 2014.

47. Raza, N.; Akbar, M.Q.; Aized Amin Soofi, S.A. Study of Smart Grid Communication Network Architectures and Technologies. Sci. Res. Publ. J. Comput. Commun. 2019, 7, 19-29. [CrossRef]

48. Ghorbanian, M.; Dolatabadi, S.H.; Masjedi, M.; Siano, P. Communication in Smart Grids: A Comprehensive Review on the Existing and Future Communication and Information Infrastructures. IEEE Syst. J. 2019, 13, 4001-4014. [CrossRef]

49. Saleem, Y.; Crespi, N.; Rehmani, M.H.; Copeland, R. Internet of Things-Aided Smart Grid: Technologies, Architectures, Applications, Prototypes, and Future Research Directions. IEEE Access 2019, 7, 62962-63003. [CrossRef]

50. Hui, H.; Ding, Y.; Shi, Q.; Li, F.; Song, Y.; Yan, J. 5G network-based Internet of Things for demand response in smart grid: A survey on application potential. Appl. Energy 2020, 257, 113972. [CrossRef]

51. Mikhaylov, K.; Petäjäjärvi, J.; Haapola, J.; Pouttu, A. D2D communications in lorawan low power wide area network: From idea to empirical validation. In Proceedings of the 2017 IEEE International Conference on Communications Workshops (ICC Workshops), Kansas City, MO, USA, 20-24 May 2017; pp. 737-742.

52. Zhou, W.; Tong, Z.; Dong, Z.Y.; Wang, Y. LoRa-Hybrid: A LoRaWAN Based multihop solution for regional microgrid. In Proceedings of the 2019 IEEE 4th International Conference on Computer and Communication Systems (ICCCS), Singapore, 23-25 February 2019; pp. 650-654.

53. Abbasi, M.; Khorasanian, S.; Yaghmaee, M.H. Low-Power Wide Area Network (LPWAN) for Smart grid: An in-depth study on LoRaWAN. In Proceedings of the 2019 5th Conference on Knowledge Based Engineering and Innovation (KBEI), Tehran, Iran, 28 February-1 March 2019; pp. 22-29.

54. Al-Turjman, F.; Abujubbeh, M. IoT-enabled smart grid via SM: An overview. Future Gener. Comput. Syst. 2019, 96, 579-590. [CrossRef]

55. Kabalci, Y. A survey on smart metering and smart grid communication. Renew. Sustain. Energy Rev. 2016, 57, 302-318. [CrossRef]

56. Sohraby, K.; Minoli, D.; Occhiogrosso, B.; Wang, W. A review of wireless and satellite-based M2M/IoT services in support of smart grids. Mob. Netw. Appl. 2018, 23, 881-895. [CrossRef]

57. Gross, S.; Ponci, F.; Monti, A. Multi-Microgrid Energy Management System in Times of 5G. In Proceedings of the 2019 IEEE International Conference on Communications, Control, and Computing Technologies for Smart Grids (SmartGridComm), Beijing, China, 21-23 October 2019; pp. 1-6. 
58. Digra, R.K.; Pandey, R.K. Multi-agent control coordination of Microgrid. In Proceedings of the 2013 Students Conference on Engineering and Systems (SCES), Allahabad, India, 12-14 April 2013; pp. 1-5.

59. Dou, C.; Liu, B. Multi-Agent Based Hierarchical Hybrid Control for Smart Microgrid. IEEE Trans. Smart Grid 2013, 4, 771-778. [CrossRef]

60. Morstyn, T.; Hredzak, B.; Agelidis, V.G. Control Strategies for Microgrids With Distributed Energy Storage Systems: An Overview. IEEE Trans. Smart Grid 2018, 9, 3652-3666. [CrossRef]

61. Hasanuzzaman Shawon, M.; Muyeen, S.M.; Ghosh, A.; Islam, S.M.; Baptista, M.S. Multi-Agent Systems in ICT Enabled Smart Grid: A Status Update on Technology Framework and Applications. IEEE Access 2019, 7, 97959-97973. [CrossRef]

62. Bag, G.; Thrybom, L.; Hovila, P. Challenges and opportunities of 5G in power grids. IET CIRED Open Access Proc. J. 2017, 2017, 2145-2148. [CrossRef]

63. Zia, M.F.; Elbouchikhi, E.; Benbouzid, M. Microgrids energy management systems: A critical review on methods, solutions, and prospects. Appl. Energy 2018, 222, 1033-1055. [CrossRef]

64. Kim, Y.J.; Wang, J.; Lu, X. A framework for load service restoration using dynamic change in boundaries of advanced microgrids with synchronous-machine DGs. Trans. Smart Grid 2016, 9, 3676-3690. [CrossRef]

65. Madureira, A.; Lopes, J.P. Ancillary services market framework for voltage control in distribution networks with microgrids. Electr. Power Syst. Res. 2012, 86, 1-7. [CrossRef]

66. Wu, Y.; Hu, W.; Yang, Z.; Jing, J.; Wu, J. Service Restoration of Active Distribution Network Considering the Islanded Operation of Distributed Generation and Micro-grid. In Proceedings of the 2018 IEEE 2nd International Electrical and Energy Conference (CIEEC), Beijing, China, 4-6 November 2018; pp. 309-313.

67. Gheisarnejad, M.; Khooban, M.H.; Dragicevic, T. The future 5G network based secondary load frequency control in maritime microgrids. IEEE J. Emerg. Sel. Top. Power Electron. 2019, 8, 836-844. [CrossRef]

68. Covatti, F.; Winter, J.M.; Muller, I.; Pereira, C.E.; Netto, J.C. Wireless communication for IEC61850: A WirelessHART gateway proposal. In Proceedings of the IEEE International Conference on Industrial Technology (ICIT), Busan, Korea, 26 February-1 March 2014; pp. 754-759.

69. Kanabar, P.M.; Kanabar, M.G.; El-Khattam, W.; Sidhu, T.S.; Shami, A. Evaluation of communication technologies for IEC 61850 based distribution automation system with distributed energy resources. In Proceedings of the 2009 IEEE Power \& Energy Society General Meeting, Calgary, AB, Canada, 26-30 July 2009; pp. 1-8.

70. Rinaldi, S.; Ferrari, P.; Ali, N.M.; Gringoli, F. IEC 61850 for micro grid automation over heterogeneous network: Requirements and real case deployment. In Proceedings of the IEEE 13th International Conference on Industrial Informatics (INDIN), Cambridge, UK, 22-24 July 2015; pp. 923-930.

71. Yang, X.; Wang, Y.; Zhang, Y.; Xu, D. Modeling and Analysis of Communication Network in Smart Microgrids. In Proceedings of the 2nd IEEE Conference on Energy Internet and Energy System Integration (EI2), Beijing, China, 20-22 October 2018; pp. 1-6.

72. Hussain, S.M.S.; Tak, A.; Ustun, T.S.; Ali, I. Communication Modeling of Solar Home System and Smart Meter in Smart Grids. IEEE Access 2018, 6, 16985-16996. [CrossRef]

73. Nagothu, K.; Kelley, B.; Jamshidi, M.; Rajaee, A. Persistent Net-AMI for Microgrid Infrastructure Using Cognitive Radio on Cloud Data Centers. IEEE Syst. J. 2012, 6, 4-15. [CrossRef]

74. Ustun, T.S.; Khan, R.H. Multiterminal hybrid protection of microgrids over wireless communications network. IEEE Trans. Smart Grid 2015, 6, 2493-2500. [CrossRef]

75. Ci, S.; Qian, J.; Wu, D.; Keyhani, A. Impact of wireless communication delay on load sharing among distributed generation systems through smart microgrids. IEEE Wirel. Commun. 2012, 19, $24-29$.

76. Oureilidis, K.O.; Demoulias, C.S. Microgrid wireless energy management with energy storage system. In Proceedings of the 47th International Universities Power Engineering Conference (UPEC), London, UK, 4-7 September 2012; pp. 1-6.

77. Liang, H.; Choi, B.J.; Zhuang, W.; Shen, X.; Awad, A.S.A.; Abdr, A. Multiagent coordination in microgrids via wireless networks. IEEE Wirel. Commun. 2012, 19, 14-22. [CrossRef]

78. Kwasinski, A.; Kwasinski, A. Operational aspects and power architecture design for a microgrid to increase the use of renewable energy in wireless communication networks. In Proceedings of the International Power Electronics Conference (IPEC-Hiroshima 2014 - ECCE ASIA), Hiroshima, Japan, 18-21 May 2014; pp. 2649-2655. 
79. Siow, L.K.; So, P.L.; Gooi, H.B.; Luo, F.L.; Gajanayake, C.J.; Vo, Q.N. Wi-Fi based server in microgrid energy management system. In Proceedings of the TENCON IEEE Region 10 Conference, Singapore, 23-26 November 2009; pp. 1-5.

80. Setiawan, M.A.; Shahnia, F.; Rajakaruna, S.; Ghosh, A. ZigBee-Based Communication System for Data Transfer Within Future Microgrids. IEEE Trans. Smart Grid 2015, 6, 2343-2355. [CrossRef]

81. Zeinali, M.; Thompson, J.; Khirallah, C.; Gupta, N. Evolution of home energy management and smart metering communications towards 5G. In Proceedings of the 2017 8th International Conference on the Network of the Future (NOF), London, UK, 22-24 November 2017; pp. 85-90.

82. Dragičević, T.; Siano, P.; Prabaharan, S. Future generation 5G wireless networks for smart grid: A comprehensive review. Energies 2019, 12, 2140.

(C) 2020 by the authors. Licensee MDPI, Basel, Switzerland. This article is an open access article distributed under the terms and conditions of the Creative Commons Attribution (CC BY) license (http:// creativecommons.org/licenses/by/4.0/). 